\title{
TEKNOLOGI BIOFERMENTASI BERBASIS IMO (INDOGENOUS MICROORGANISM) UNTUK MEMBUAT PUPUK ORGANIK DI UD TIMAN AGUNG KELATING TABANAN
}

\author{
N.W. Siti ${ }^{1}$, N.M. Witariadi ${ }^{2}$, N.N.Soniari ${ }^{3}$ dan N. K. Seminari ${ }^{4}$
}

\begin{abstract}
ABSTRAK
Pengabdian yang bertujuan untuk meningkatkan pengetahuan dan keterampilan karyawan UD Timan Agung tentang Teknologi Biofermentasi berbasis IMO (Indogenous Microorganism) untuk membuat pupuk organik padat dan cair. Pengabdian telah dilaksanakan mulai bulan mei sampai bulan September 2018. Metode yang dilakukan adalah penyuluhan dan demonstrasi tentang teknologi biofermentasi berbasis IMO. Teknologi yang didemonstrasikan adalah teknologi sederhana yang sudah biasa dilakukan oleh karyawan UD Timan Agung. Hasil dari pengabdian adalah : (1) satu paket Bioreaktor; (2) SOP inokulan dari mikroorganisme lokal, (3) SOP pupuk organik padat, dan (4) hasil analisapupuk organik padat. Kesimpulan dari pengabdian adalah terwujudnya satu paket bioreaktor untuk membuat inokulan berbasis IMO, karyawan CV Timan Agung mampu membuat inokulan berbasis IMO (Indogenous Mikroorganism)dan sudah mempunyai Standar Operasional Prosedur (SOP) untuk memproduksi pupuk organik menuju SNI.
\end{abstract}

Kata kunci : bioreaktor, inokulan,pupuk organik,UD Timan Agung, desa Klating

\begin{abstract}
Devotion that aimed to increase the knowledge and skills of UD Timan Agung employees about IMO (Indogenous Microorganism) based Biofermentation Technology to make solid and liquid organic fertilizers. Service has been carried out from May to September 2018. The method used were counseling and demonstration on IMO-based biofermentation technology. The technology that was demonstrated was a simple technology that was commonly used by UD Timan Agung employees. The results of the service are: (1) a package of Bioreactors; (2) SOP of inoculants from local microorganisms, (3) SOP of solid organic fertilizers, and (4) results of analysis of solid organic fertilizers. The conclusion of the service was the realization of a bioreactor package to make IMO-based inoculants, CV Timan Agung employees were able to make inoculants according to SOP and process organic fertilizers according to the SOP towards SNI.
\end{abstract}

Keywords:bioreactor, inoculant, organic fertilizer, UD Timan Agung, Klating village

\footnotetext{
${ }^{1}$ Dosen Program Studi Sarjana Peternakan Fakultas Peternakan Universitas Udayana,wayansiti@unud.ac.id

${ }^{2}$ Dosen Program Studi Sarjana Peternakan Fakultas Peternakan Universitas Udayana, witarimade@yahoo.com

${ }^{3}$ Dosen Program Studi Agroekoteknologi Fakultas Pertanian Universitas Udayana,nengahsonari@unud.ac.id

${ }^{4}$ Dosen Program Studi Manajemen Fakultas Pertanian dan Bisnis Universitas udayana,ktseminari@unud.ac.id
} 


\section{PENDAHULUAN}

Keberhasilan program pertanian organik membutuhkan penanganan secara holistik dari hulu hingga hilir, kebijakan pertanian organik tidak dapat dipisahkan dari industri pupuk organik. Penyediaan pupuk organik dan biopestisida sebagai input utama dari pertanian organik secara tepat, baik dalam jumlah, waktu dan kualitas sangat diperlukan (Sardiana, dkk. 2014). Standar kualitas maksudnya adalah harus memiliki sertifikat sesuai Standar Nasional Indonesia (SNI). Kebijakan subsidi pupuk organik Kabupaten Tabanan diproduksi oleh UKM produsen pupuk organik dan gabungan kelompok tani

Sistem Pertanian Terintegrasi (Simantri). Salah satu UKM produsen pupuk yang terbesar dan menjadi pemasok utama kebutuhan pupuk organik baik untuk tujuan subsidi pemerintah maupun pasar umum adalah CV. Timan Agung. UKM ini beralamat di Desa Klating, Kecamatan Kerambitan, Kabupaten Tabanan. UKM ini berdiri sejak tahun 2010, memproduksi pupuk organik padat dan cair (biourine) serta biopestisida dengan kapasitas mencapai 2.000 ton pupuk organik/tahun dan 5000 liter biopestisida/tahun. Permasalahan yang dihadapi oleh UKM Timan Agung, dan petani terutama penyediaan pupuk yang belum memenuhi standar kualitas SNI. Permasalahan lain yang harus diselesaikan oleh pengelola UKM ini adalah minimnya teknologi dalam produksi biopestisida dari bahan lokal. Dalam hal ini sangat diperlukan adanya keterlibatan perguruan tinggi dalam mensolusikan persoalan tersebut. Peran perguruan tinggi terutama dalam difusi teknologi biofermentasi berbasis IMO (indegenous mocroorganism) untuk menghasilkan pupuk organik dan biopestisida berbahan lokal yang sesuai standar kualitas SNI.

Universitas Udayana melalui para dosen dari Fakultas Perternakan secara aktif melakukan berbagai penelitian untuk menciptakan dekomposor unggul yang mampu bekerja efektif untuk memproduksi pupuk yang berkualitas. Mikroba unggul telah diseleksi dan dikarakterisasi aktivitas enzimatikanya sesuai dengan peruntukannya sebagai agen penyubur tanaman, biokontrol dan bioremediasi lahan. Pupuk organik berkualitas berarti bahwa pupuk tersebut sesuai standar nasional Indonesia (SNI) serta mengandung hara tanaman yang lebih lengkap dengan dosis yang lebih tinggi. Dekomposer unggul maksudnya mikroba pengurai yang mampu menguraikan bahan organik secara lebih sempurna dalam waktu yang lebih singkat. Starter yang dipakai berasal dari mikroba unggul hasil kultur dosen peneliti Universitas Udayana yang sedang dalam proses pengajuan paten. Produk tersebut mengandung polimikroorganisme, lignolitik, proteolitik, amilolitik, sellulolitik, lipolitik dan nitrogen non simbiotik yang dapat mempercepat proses fermentasi (pengomposan). Pengomposan adalah penerapan IPTEK memakai bakteri fibrolitik yang akan mengurai bahan sintesis, senyawa kompleks dan pestisida dengan cepat, hanya waktu 7 14 hari sudah menjadi pupuk organik. Pengomposan adalah upaya menurunkan rasio $\mathrm{C} / \mathrm{N}$ bahan menjadi $10-20$, sehingga dapat diserap tanah. Proses penguraian dipercepat dengan menambah starter, kultur bakteri sebagai dekomposer.

Menurut SNI 19-7030-2004 kandungan hara pupuk organik menliputi: kadar air maksimum 50\%; suhu sesuai dengan suhu air tanah; warna kehitaman; berbau tanah; ukuran partikel 0,55- $25 \mathrm{~mm}$; kemampuan ikat air minimum 58\%; pH 6,8-7,49; bahan asing maksimal 1,5\%; bahan organik 27$58 \%$; nitrogen 0,4\%; karbon 9,8-32\%; posfor (P2O5)0,1\%; C/N rasio 10-20\%; kalium (K2O) 0,20\%; Arsen maksimum $13 \mathrm{mg} / \mathrm{kg}$; cadmium (Cd) maks. $3 \mathrm{mg} / \mathrm{kg}$; kobal (Co) maks. $34 \mathrm{mg} / \mathrm{kg}$; kromium (Cr) maks. $210 \mathrm{mg} / \mathrm{kg}$; tembaga $(\mathrm{Cu})$ maks. $100 \mathrm{mg} / \mathrm{kg}$; merkuri $(\mathrm{Hg})$ maks. 0,8 mg/kg; nikel (Ni) maks. $62 \mathrm{mg} / \mathrm{kg}$; timbal (Pb) maks. $150 \mathrm{mg} / \mathrm{kg}$; selenium (Se) maks. $2 \mathrm{mg} / \mathrm{kg}$; Seng (Zn) maks. $500 \mathrm{mg} / \mathrm{kg}$; kalsium (Ca) maks. 25,50\%; besi ( $\mathrm{Fe}$ ) maks. 0,6 \%; Aluminium (Al) maks. 2,2\%; Mangan (Mn) maks. 0,1\%; Fecal coli maks. 1000 MPN/g dan Salmonella sp maks. 3 $\mathrm{MPN} / 4 \mathrm{~g}$. 
Berdasarkan uraian di atas maka UKM CV Timan Agung perlu didampingi dalam memproduksi pupuk organik mempunyai SOP mengacu standar SNI dan memproduksi inokulan dari mikroorganisme lokal.

\section{METODE PELAKSANAAN}

Ada dua hal yang perlu diperhatikan dalam menerapkan teknologi pada industri mitra. Pertama, teknologi yang digunakan adalah teknologi-teknologi sederhana dan sudah dikenal oleh pekerja UKM sehingga mudah dikerjakan. Kedua, teknologi yang dipilih tidak memberikan biaya tambahan yang sangat membebani dan secara ekonomi merugikan usaha industri mitra.Teknologi yang diaplikasikan pada kegiatan ini terdiri dari : (1) rakitan teknologi biofermentasi berbasis IMO hasil isolasi dan pengembangan PT; dan (2) rakitan teknologi pupuk organik.

Rakitan teknologi produksi stater/decomposer berbasis IMO merupakan teknologi probiotik dengan memanfaatkan bioinokulan hasil isolasi dan kultur Perguruan Tinggi. Bioinokulan tersebut mengandung polimikroorganisme, lignolitik, proteolitik, amilolitik, sellulolitik, lipolitik dan nitrogen non simbiotik yang dapat mempercepat proses fermentasi (pengomposan).

\section{HASIL DAN PEMBAHASAN}

Kegiatan pengabdian yang berjudul Teknologi Biofermentasi berbasis IMO untuk membuat pupuk organik di CV Timan Agung, telah dilaksanakan mulai dari bulan Mei sampai September 2018.Kegiatan yang dilakukan meliputi: penyuluhan dan demontrasi tentang rakitan teknologi biofermentasi berbasis IMO hasil isolasi dariPerguruan Tinggi dan produksi pupuk organik yang sesuai dengan standar Nasional Indonesia (SNI). Rakitan teknologi yang dihasilkan adalah:(1) satu paket bioreaktor untuk menghasilkan fermentor yang berbasis IMO yang mengandung multi mikroba. Bioreaktor dirancang dari bahan-bahan seperti : tangki, motor penggerak, batang besi, pengaduk, saluran respirasi. Bioreaktor adalah sebuah peralatan atau sistem yang mampu menyediakan sebuah lingkungan biologis untuk menunjang terjadinya reaksi biokimia dari bahan mentah menjadi bahan yang dikehendaki. Bahan-bahan untuk membuat fermentor : ekstrak daun kelor $25 \%$, molasses $5 \%$, gula pasir/merah $5 \%$, kaldu keong mas $15 \%$, tepung kue $0,5 \%$, tepung agar-agar 0,05\% dan air kelapa 49,25\% serta mikroba Bacillus sp. dari cairan rumen 0,2\% (untuk membuat 100 liter). Metode pembuatannya : ekstrak daun kelor + larutan gula (molasses+gula)+ kaldu keong mas + tepung agar + tepung kue + isolate Bacillus sp + air kelapa. Semua bahan-bahan dimasukkan ke dalam bioreactor yang sudah dilengkapi dengan mesin pengaduk, diaduk setiap hari selama 21 hari. Setelah 21 hari fermentor sudah jadi dan siap dikemas untuk dijual. (2) Pupuk bioorganik padat yang difermentasi dengan inokulan berbasis IMO hasil isolasi dari Perguruan Tinggi. Produksi $100 \mathrm{~kg}$ pupuk organik padat bahan-bahan : kotoran sapi $40 \%$, kotoran ayam $35 \%$, ampas anggur 5\%, serbuk gergaji 10\%, arang sekam 5\% dan fermentor ) $0,2 \%+$ molasses $4,8 \%$, Metode pembuatannya kotoran dicampur dengan serbuk gergaji kayu + ampas anggur + arang sekam, dicampur sampai homogen, setelah tercampur disemprot dengan fermentor + molasses, diaduk sampai semua tercampur dengan fermentor, lalu ditutup, disimpan selama 21 hari. Setelah 21 hari dibuka, diangin-anginkan selama 3-5 jam, diayak agar halus, lalu dikemas, siap dijual.

Hasil analisis laboratorium pupuk organik padat : $\mathrm{pH} 8,01$; kadar air $22,13 \%$; temperatur $27,1^{\circ} \mathrm{C}$; warna hitam; bahan organik $37,27 \%$; $\mathrm{C}$ organik $21,62 \% ; \mathrm{N}$ total $0,58 \% ; \mathrm{C} / \mathrm{N}$ ratio 36,$98 ; \mathrm{P} 2 \mathrm{O} 5$ 1,01\%; K2O 1,86\%; Fe total 9507,7 ppm; Mn total 427,7 ppm; Zn total 149,9 ppm; Faecal coliform > 1100 MPN/gram dan Salmonella sp /25 gram: negatif(Laboratorium SUCOFINDO, 2018). Hasil ini sudah sesuai dengan Standar Nasional Indonesia (SNI), seperti kadar air, pH, warna, bahan organik, $\mathrm{C}$ organik, $\mathrm{N}$ total, $\mathrm{Fe}$, bakteri Coliform dan Salmonella, kecualiC/N ratio diatas $20 \%$. Hal ini ada hubungannya dengan populasi mikroba pada pupuk tinggi, sebagian besar $\mathrm{N}$ total digunakan sebagai sumber protein untuk memperbanyak sel, akibatnya $\mathrm{N}$ total rendah dan

\section{BULETIN UDAYANA MENGABDI}


bahan $\mathrm{C}$ organik yang dihasilkan tinggi yang berakibat $\mathrm{C} / \mathrm{N}$ ratio tinggi. Pupulasi mikroba tinggi pada pupuk berdampak positip pada tanah, karena mikroba tersebut mampu memanfaatkan $\mathrm{N}$ dari udara dan tanah. Hal ini terbukti dari efek pupuk organik berlahan-lahan, sekarang ditebar efeknya sampai kepanen berikutnya. Usaha yang dilakukan untuk memenuhi SNI adalah dengan menambahkan sumber $\mathrm{N}$ seperti kotoran ayam dan menyimpan pupuk dalam keadaan anaerob pada waktu sekitar 8-12 minggu agar didapat $\mathrm{C} / \mathrm{N}$ ratio sesuai standar. Pelaksanaan kegiatan di $\mathrm{CV}$ Timan Agung dapat dilihat pada Gambar 3.1;3.2 ;3.3;3.4;3.5 dan 3.6.

\section{KESIMPULAN DAN SARAN}

Kesimpulan yang bisa diambil dari kegiatan pengabdian hi-link adalah: (1) Tingkat pengetahuan karyawan UD Timan Agungtentang pemahaman teknologi bioreactor utnuk menghasilkan inokulan berbasis IMO (Indogenous Mcroorganism) meningkat.Terwujud satu paket bioraktor yang sudah mampu menghasilkan inokulan berbasis IMO (Indogenous Microorganism). UD Timan Agung sudah mempunyai SOP untuk memproduksi pupuk organik padat menuju Standar Nasional Indonesia (SNI).

Saran yang dapat diajukan adalah perlu dilakukan pendampingan secara berkelanjutan agar inovasi yang diberikan dapat diterapkan secara tepat guna sehingga UD Timan Agung menghasilkan produk yang berkualitas sesuai SOP menuju Standar Nasional Indonesia (SNI).

Pelaksanaan kegiatan pengabdian ini dapat dilahat pada Gambar 3.1-3.6

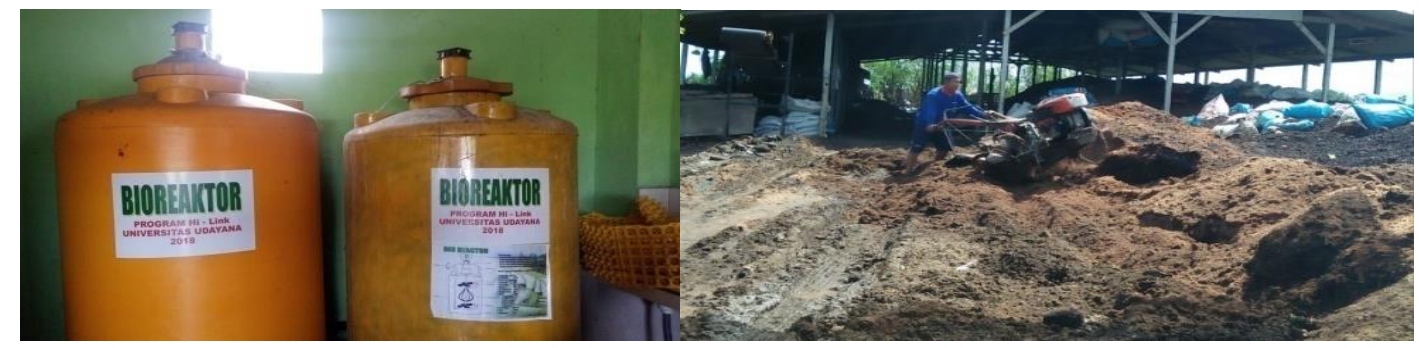

Gambar 3.1 Bioreaktor

Gambar 3.2. Pencampuran bahan baku pupuk

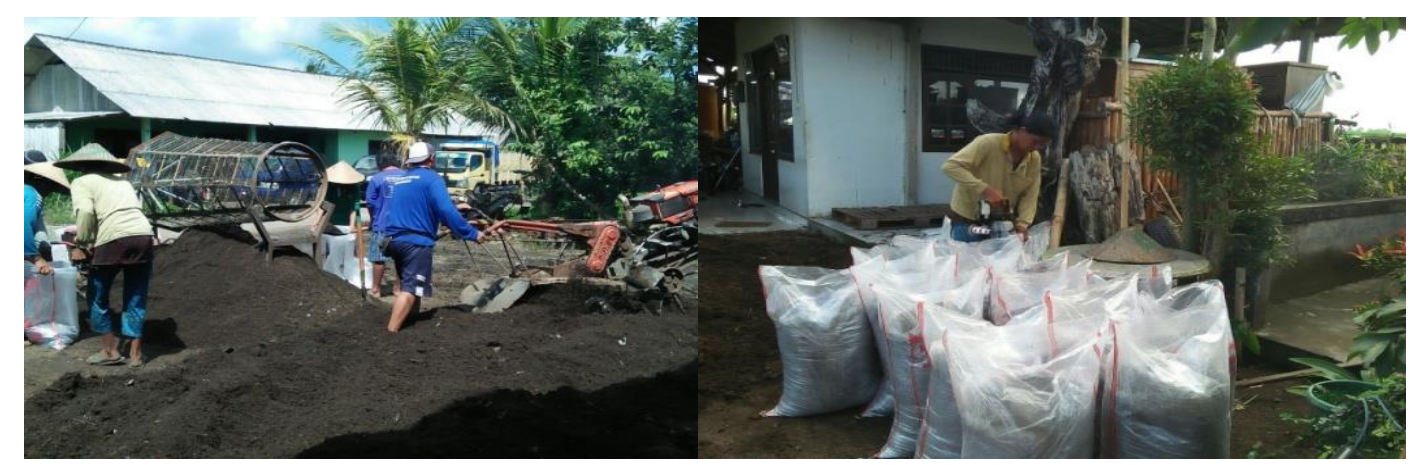

Gambar3.3. Pupuk yg sudah kering di ayak

Gambar 3.4. Pengemasan pupuk 


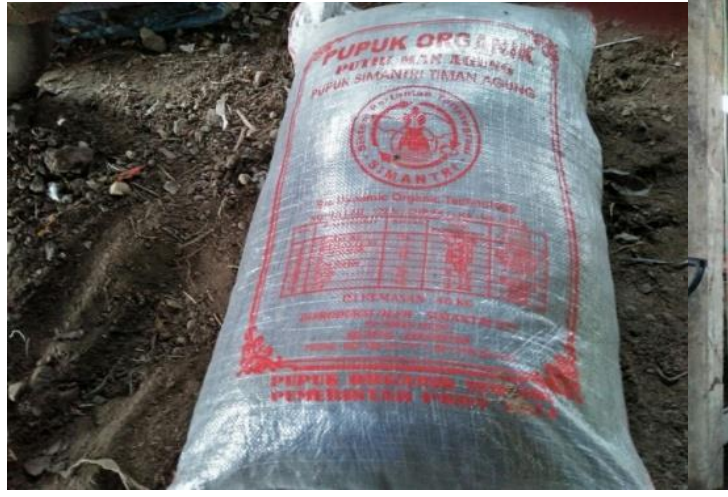

Gambar 3.5. Pupuk yang sudah dikemas

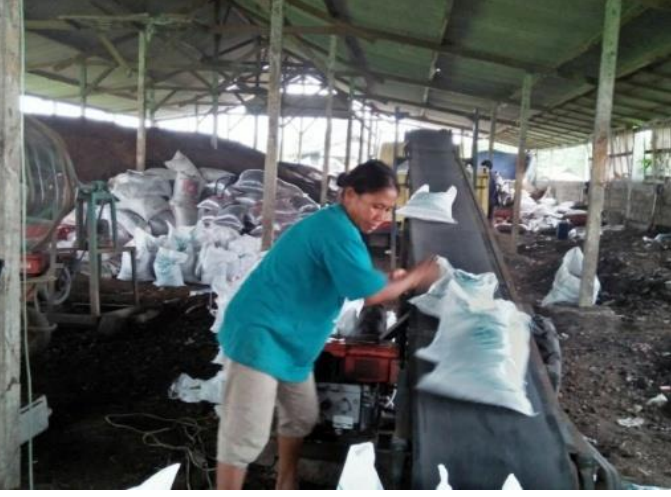

Gambar 3.6. Pupuk siap didistribusikan

\section{UCAPAN TERIMA KASIH}

Penulis mengucapkan terima kasih kepada KEMENRISTEK DIKTI atas dana yang diberikan lewat program Hi-Link, Rektor Universitas Udayana, Ketua LPPM beserta staf terima kasih atas seleksi proposal dan tenaga yang diberikan dalam pelaksanaan di lapangan, sehingga pengabdian kepada masyarakat terlaksana sesuai rencana.

\section{DAFTAR PUSTAKA}

Baiquni, M. 1999. Participatory Rural Appraisal, Metode dan Teknik Partisipasidalam Pengembangan Perdesaan. Jogjakarta : UGM Press.

Chambers, Robert. 1987 Pembangunan Desa Mulai dari Belakang. (Pepep Sudradjat, penerjemah). Jakarta : LP3ES.

Daldjoeni, N. dan A. Soeyitno. 1978. Pedesaan, Lingkungan, dan Pembangunan. Bandung : Alumni.

David, F. R. 2002. Manajemen Strategis: Konsep. (Terjemahan oleh Sindoro A.). Jakarta: PT. Ikrar Mandiri.

Korten, David C. dan Syahrir. 1988. Pembangunan Berdimensi Kerakyatan. Jakarta : Yayasan obor Indonesia.

Rangkuti, F. 2000. Analisis SWOT: Teknik Membedah Kasus Bisnis. Jakarta: Gramedia Pustaka Utama.

Sardiana, I.K., I.M. Adnyana, I.B.P. Manuaba and I.G.A.M S Agung. 2014. Soil Organic Carbon, Labile Carbon and Organic Carbon Storage under Organic and Conventional Systems of Chinese Cabbage in Baturiti, Bali Indonesia. Journal of Biology, Agriculture and Healthcare. Vol. 4. No. 21. Pp. 63-71

Sumodiningrat, Gunawan. 1999. Pemberdayaan Masyarakat dan Jaring Pengaman Sosial. Jakarta : PT. Gramedia Pustaka Utama.

Suriadikarta, DA dan D Setyorini. 2005. Laporan Hasil Penelitian Standar Mutu Pupuk Organik. Balai Penelitian Ternak, Bogor. 